FORMATION Formation emploi

Revue française de sciences sociales

105 | janvier-mars 2009

Pêle-mêle

\title{
Au-delà des statuts : la diversité des pratiques
}

Jean-Frédéric Vergnies

\section{(2) OpenEdition}

Journals

Édition électronique

URL : http://journals.openedition.org/formationemploi/1791

DOI : 10.4000/formationemploi.1791

ISSN : 2107-0946

\section{Éditeur}

La Documentation française

\section{Édition imprimée}

Date de publication : 1 mars 2009

Pagination : 1

ISSN : 0759-6340

\section{Référence électronique}

Jean-Frédéric Vergnies, «Au-delà des statuts : la diversité des pratiques », Formation emploi [En ligne], 105 | janvier-mars 2009, mis en ligne le 12 novembre 2009, consulté le 30 octobre 2020. URL : http:// journals.openedition.org/formationemploi/1791 ; DOI : https://doi.org/10.4000/formationemploi.1791 


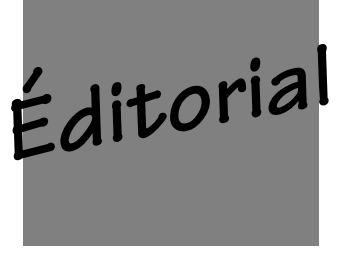

\title{
Au-delà des statuts : la diversité des pratiques
}

\begin{abstract}
es politiques publiques ou les politiques de gestion de la main-d'œuvre renvoient le plus souvent aux statuts des personnes : position sur le marché du travail, catégorie d'emploi. Ainsi nombre de dispositifs publics sont d'abord fondés sur le statut des personnes ; l'accès à une formation (et à son financement) sera conditionné à la position sur le marché du travail (lycéen, chômeur, en CDD ou en CDI, voire l'appartenance à la catégorie " publics en difficulté », ou le niveau de formation). Ces catégories fondent bien souvent nos analyses et par conséquent les actions qui en découlent.
\end{abstract}

La lecture de ce numéro de Formation Emploi invite à relativiser notre approche très statutaire de la relation formation-emploi-travail, tout comme son pendant fondé sur l'initiative individuelle qui serait formalisée dans un projet personnel.

Ainsi l'analyse de la (non) participation à la formation continue des travailleurs dits précaires montre que le statut du contrat de travail ne saurait être le déterminant principal de ce non-accès à la formation. Coralie Perez souligne notamment la diversité des trajectoires individuelles et conclut en rappelant que la formation ne saurait constituer une réponse univoque à la précarité de l'emploi.

La question de l'accès au stage des jeunes en formation professionnelle est tout aussi cruciale. Nicolas Farvaque examine les difficultés des jeunes issus de l'immigration et celles des équipes enseignantes à aider ces jeunes à obtenir un stage. Les responsables de stages oscillent bien souvent entre une logique pédagogique articulée autour de la construction d'un projet et une logique de placement.

Les trois articles suivant invitent à relativiser les rapprochements entre niveau de formation et devenir des personnes, notamment en termes de statut professionnel.

Armelle Gorgeu et René Mathieu, en analysant la situation des ouvriers dans le secteur automobile, Paul Santelman, en revenant sur l'exemple des techniciens et agents de maîtrise de type industriel, soulignent la diversité des pratiques et des situations. Les premiers s'attachent à une explicitation de la diversité des politiques de gestion de la main-d'œuvre. Le second appelle au final à dépasser une conception des diplômes fondée sur le cloisonnement vertical et pyramidal, la rigidité des frontières catégorielles et fonctionnelles.

Pour sa part, Oumaya Hidri montre que pour favoriser l'insertion professionnelle des jeunes issus de l'enseignement supérieur, il ne suffirait pas de pallier l'écart entre leurs profils (leur niveau de diplôme) et les attentes affichées des recruteurs. Au final, les pratiques des recruteurs reposent sur leurs représentations concernant aussi bien l'origine et le milieu social, la formation-certification, les expériences professionnelles que la personnalité des candidats ; représentations qui les conduisent bien souvent à privilégier un " autre soi-même».

Aussi ces articles soulignent l'importance de la diversité des pratiques et la nécessité d'actions concertées et mutualisées.

En vous souhaitant une bonne lecture et une bonne année sous le signe du neuf. 